\title{
MONITORING SYSTEM OF FUNCTIONAL ABLLITY OF UNIVERSITY STUDENTS IN THE PROCESS OF PHYSICAL EDUCATION
}

\author{
Ivan Samokish, 1, A, B, C, D Anatoly Bosenko, , A, B, E Oleksandr Pryimakov, , , D, E \\ Viktoriya Biletskaya ${ }^{4, C, E}$
}

\author{
${ }^{1}$ A.S. Popov Odessa National Academy of Telecommunications, Ukraine \\ ${ }^{2}$ South National Pedagogical University named after K.D. Ushinsky, Ukraine \\ ${ }^{3}$ Faculty of Physical Culture and Health Promotion, University of Szczecin, Poland \\ ${ }^{4}$ National Aviation University (NAU) Kiev, Ukraine

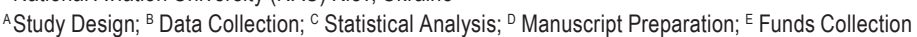 \\ Address for corpespondence: \\ Ivan Samokish \\ A.S. Popov Odessa National Academy of Telecommunications \\ Kuznechnaya str. 1, Odesa, 65029, Ukraine \\ Email: samokih@i.ua
}

\begin{abstract}
Ahstract Given research is devoted to the regional criteria development for evaluation of educational achievements and preparation of practical recommendations for teachers of higher educational institutions on the application of methodology for assessing the functional opportunities in process of physical education. During the research evaluation standards of functional opportunities of students were developed with the usage of mathematical statistics on the basis of the average arithmetic value $(M)$ and standard deviation ( $\sigma)$. The study involved 150 students ( 86 girls and 64 boys, who belonged to the main medical group).Appropriate norms provide more complete information about positive (negative) changes of functional opportunities' level compared with traditional pedagogical tests. There are represented practical recommendations on the usage of functional testing during training sessions at universities in order to optimize the process of physical education.
\end{abstract}

Key Worlds students, physical education, functional testing, academic achievement, functional abilities, physical health

\section{Introduction}

For successful implementation of their profession in Ukraine graduates of higher education institutions need to have good health and sufficient level of physical performance. The main role in solving this problem is played by formation of students' healthy lifestyle. The main source of information about health are education classes on physical education, especially methodological and practical and educational training sessions.

In Ukraine during the years of independence there was some system of physical education of students the general features of which are fixed by number of regulation documents (Domashenko, Raievs'ky, Kanishevs'ky, 2003; Operaylo, 2006). The Provision about the organization of physical training and mass sports in universities 
sets the total amount of mandatory lessons of physical training in universities, which is at least 4 hours a week, except for the last semester of graduation course (Domashenko, Raievs'ky, Kanishevs'ky, 2003). Estimation of learning achievements in higher education in accordance with the provision of the exhibiting credits in physical education provides for a complex monitoring on the basis of indicators of physical fitness, technical performance of motor actions and theoretical training. A key components of the estimation of educational achievements are tests and assessment standards of physical fitness of students, developed in higher education in coordination with the ministry or agency to which they are subordinated (Domashenko, Raievs'ky, Kanishevs'ky, 2003). Given that developed by higher education institution regulations in some cases do not have enough scientific and practical justification and in general give a superficial knowledge of the physical condition and efficiency of students, it is possible to use functional tests on practical lessons on physical education.

A variety of methods caused differences represented in literature in terms of physical performance, even such as PWC170. This leads into the category of topical tasks necessity of improvement and unification of methods for determining the functional abilities of students.

In our opinion (Bosenko, Samokish, Dubinin, 2008; Samokysh, 2005; Samokysh, Bosenko, 2009) the most accurate, efficient and informative is cyclical handling test (Davidenko, Andrianov, Yakovlev, 1984), in which the power of exercise varies by closed cycle. This method allows detecting not only indicators of physical efficiency and response of the cardiovascular system, but also allows to set regulatory and energy components of the system reaction of the human body. However, qualifications for athletes, require the development of criteria for estimation and adapting it for research the students during physical education classes.

\section{Material and methods}

Regional criteria for assessment of student achievement and prepare practical recommendations for teachers of higher educational institutions and application of evaluation methods of functional abilities in a process of physical education need to be developed. The study involved 150 students of first and second courses aged 18-19 years, who studied in the South National Pedagogical University named after K.D. Ushinsky (c. Odessa) and A.S. Popov Odessa National Academy of Telecommunications. During the research methodology of Davidenko, Andrianov, Yakovlev (1984) was used. The load was set on ergometers at a frequency of pedaling $60 \mathrm{rev} / \mathrm{min}$. Power of physical load initially increased from zero with the set speed of $33 \mathrm{~W} \cdot \mathrm{min}^{-1}$ to planned values (HR $\left.=153-156 \mathrm{~b} \cdot \mathrm{min}^{-1}\right)$, and then decreased at the same speed to zero. The meaning of the method is a graphical record in two-co system of frequency of heart rate depending on the power load and set on ergometer.

\section{Resullts}

Studies have shown that settings of functional abilities received during bicycle exercise load with the change of power in a closed loop during physical education classes in high school to assess educational progress can successfully be used. The modified method allowed obtaining indicators of systemic reactions, as tensions of functions when performing load tests, energy, regulatory components of cardiac activity and a number of indicators of overall physical efficiency. After the test results can be obtained in printed form in 5-10 sec. Studied informational content about 25 test parameters that characterize the functional abilities of the students.

The corresponding indicators of functional test play a role of criteria play in the estimation of educational achievements but their information content is not the same: high, medium and low. That's why on base of correlation 
- regression and factor analysis we selected the most informative indicators that reflect the different sides of the level of functional abilities. Assessment is made with the help of special developed evaluation standards for boys and girls aged from 18 to 19 years (Table 1, 2).

Tahle 1. Evaluation standards of functional abilities of students in higher education institutions

\begin{tabular}{|c|c|c|c|c|c|}
\hline \multirow{2}{*}{ Indexes } & \multicolumn{5}{|c|}{ MARKS, POINTS } \\
\hline & 1 & 2 & 3 & 4 & 5 \\
\hline $\mathrm{PWC}_{170}, \mathrm{~W}$ & $<204.80$ & $204.90-214.90$ & $215.00-235.00$ & $235.10-245.10$ & $>245.20$ \\
\hline$W_{\text {rev }}, W$ & $<159.80$ & $159.90-169.90$ & $170.00-186.00$ & $186.10-194.10$ & $>194.20$ \\
\hline $\mathrm{HR}_{\text {thresh }}, \mathrm{b} \cdot \mathrm{min}^{-1}$ & $>101.20$ & $96.10-101.10$ & $86.00-96.00$ & $80.90-85.90$ & $<80.80$ \\
\hline $\mathrm{HR}_{\text {out }}, \mathrm{b} \cdot \mathrm{min}^{-1}$ & $>124.20$ & $118.10-124.10$ & $106.00-118.00$ & $99.90-105.90$ & $<99.80$ \\
\hline $\mathrm{HR}_{\mathrm{ave}}, \mathrm{b} \cdot \mathrm{min}^{-1}$ & $>134.20$ & $128.10-134.10$ & $116.00-128.00$ & $109.90-115.90$ & $<109.80$ \\
\hline $\mathrm{S}_{1}, \mathrm{~W} \cdot \mathrm{min}^{-1}$ & $<3252.00$ & $3253.00-3453.00$ & $3454.00-3854.00$ & $3855.00-4055.00$ & $>4056.00$ \\
\hline $\mathrm{T}_{\mathrm{it}}, \mathrm{S}$ & $<37.80$ & $37.90-39.90$ & $44.00-48.00$ & $48.10-50.10$ & $>50.20$ \\
\hline $\mathrm{C}_{\text {eff, }}, \mathrm{c}$.u. & $>0.12$ & $0.10-0.11$ & $0.07-0.09$ & $0.05-0.06$ & $<0.04$ \\
\hline$W_{\max }, W$ & $<203.80$ & $203.90-214.90$ & $114.00-236.00$ & $236.10-247.10$ & $>247.20$ \\
\hline$W_{\text {out }}, W$ & $<189.80$ & $189.90-199.90$ & $200.00-220.00$ & $220.10-230.10$ & $>230.20$ \\
\hline$W_{1 \text { out }}, \mathrm{J}$ & $<1.20$ & $1.21-1.22$ & $1.23-1.25$ & $1.26-1.27$ & $>1.28$ \\
\hline$W_{2 \text { out }}, \mathrm{J}$ & $<1.08$ & $1.09-1.19$ & $1.20-1.22$ & $1.23-1.24$ & $>1.25$ \\
\hline Possible amount of points & $1-12$ & 13-24 & 25-36 & $37-48$ & $49-60$ \\
\hline
\end{tabular}

The scorecard includes the following indicators: physical efficiency $\mathrm{PWC}_{170}$ and $\mathrm{W}_{\text {rev }}$, threshold pulse $H R_{\text {thresh }}$, heart rate at the time of completion of the load, testing $-H R_{\text {out }}$, arithmetic average of pulse beats for functional test $-H R_{\text {ave }}$, rate of redistribution of power of heart rate $(H R)$ in the full cycle of testing $-S_{1}$, inertia time $-T_{i t}$, efficiency of ratio regulation of cardiac activity $-C_{\text {eff }}$, the level of internal power at the time of the reverse $W_{\text {rev }}$, level of internal power at the end of testing $-W_{\text {out }}$, outer work of heartbeat by increasing the load $-W_{1 \text { out }}$, outer work of heartbeat by decreasing the load $-W_{2 o u t}$.

Tahle 2. Evaluation standards of functional abilities of students in higher education institutions

\begin{tabular}{|c|c|c|c|c|c|}
\hline \multirow{2}{*}{ Indexes } & \multicolumn{5}{|c|}{ MARKS, POINTS } \\
\hline & 1 & 2 & 3 & 4 & 5 \\
\hline $\mathrm{PWC}_{170}, \mathrm{~W}$ & $<156.80$ & $156.70-165.70$ & $165.80-184.20$ & $184.30-193.50$ & $>193.60$ \\
\hline$W_{\text {rev }}, W$ & $<141.20$ & $141.30-149.60$ & $149.70-166.30$ & $166.40-174.70$ & $>174.80$ \\
\hline $\mathrm{HR}_{\text {thresh }}, \mathrm{b} \cdot \mathrm{min}^{-1}$ & $>103.20$ & $98.10-103.10$ & $88.00-98.00$ & $82.90-87.90$ & $<82.80$ \\
\hline $\mathrm{HR}_{\text {out }}, \mathrm{b} \cdot \mathrm{min}^{-1}$ & $>131.20$ & $125.10-131.10$ & $113.00-125.00$ & $106.90-112.90$ & $<106.80$ \\
\hline $\mathrm{HR}_{\mathrm{ave}}, \mathrm{b} \cdot \mathrm{min}^{-1}$ & $>140.20$ & $134.10-140.10$ & $122.00-134.00$ & $115.90-121.90$ & $<115.80$ \\
\hline $\mathrm{S}_{1}, \mathrm{~W} \cdot \mathrm{min}^{-1}$ & $<2984.00$ & $2985.00-3169.00$ & $3170.00-3538.00$ & $3539.00-3723.00$ & $>3724.00$ \\
\hline $\mathrm{T}_{\mathrm{it}}, \mathrm{s}$ & $<36.80$ & $36.90-38.90$ & $39.00-43.00$ & $43.10-45.10$ & $>45.20$ \\
\hline $\mathrm{C}_{\text {eff, }}$ c.u. & $>0.13$ & $0.11-0.12$ & $0.08-0.10$ & $0.06-0.07$ & $<0.05$ \\
\hline$W_{\max }, W$ & $<190.80$ & 190.90-200.90 & $201.00-221.00$ & $221.10-231.10$ & $>231.20$ \\
\hline $\mathrm{W}_{\text {out }}, \mathrm{W}$ & $<174.80$ & $174.90-184.90$ & $185.00-205.00$ & $205.10-215.10$ & $>215.20$ \\
\hline$W_{1 \text { out }} \mathrm{J}$ & $<0.90$ & $0.91-1.01$ & $1.11-1.31$ & $1.32-1.42$ & $>1.43$ \\
\hline$W_{2 \text { out }}, J$ & $<0.97$ & $0.98-1.08$ & $1.09-1.29$ & $1.30-1.40$ & $>1.41$ \\
\hline Possible amount of points & $1-12$ & $13-24$ & $25-36$ & $37-48$ & $49-60$ \\
\hline
\end{tabular}


For according tables, individual indicators are considered average if the same points with the average value $(M)$ and are in the range $M \pm 0.5 \sigma$. When finding values within $M-0.5 \sigma \ldots M-1 \sigma$ and $M+0.5 \sigma \ldots M+1 \sigma$ functional indicator is considered lower or above average, respectively, while the difference of $+1 \sigma$ and higher and from $-1 \sigma$ and lower - high or low. If the regression indicator, that is, the smaller the certain parameter, the higher its manifestations (e.g. heart rate indicators during exercise testing), were used the following gradation: the level below average and above average determined by range $M+0.5 \sigma \ldots M+1 \sigma$ and $M-0.5 \sigma \ldots M-1 \sigma$, low or high respectively from $+1 \sigma$ and higher and from $-1 \sigma$ and lower.

With the help of developed evaluation standards for physical education teacher can get a more complete and accurate information about the level of functional abilities of students which expressed qualitatively and quantitatively for sum of points.

We offer the following practical advice on assessment of student achievement in high school.

1. Evaluation of functionality should be spent in the classroom for physical education, in some cases after school. The organizers of testing of physical education are teachers who mastered technique well. Testing should be held in the gym or the premises, the presence in several high school of ergometer software. The students of preparatory and special medical groups performing functional tests with the permission of the doctor, it is desirable that a medical professional was there during the test. Previously, before the test at the beginning of the school year, held the meetings to inform students about the related activities.

2. We propose to held a staged, current and operational control of functional ability level. Staged control need to held 3 times during the school year. In the first stage (the second half of September) is defined the output level by indicators of bicycle exercise testing. In the second (beginning of December) and third (second half of April) stages are assessed change of functional ability of students during training. Current control need to held one time a month to identify the level of changes on adaptive abilities in the dynamics of the learning process. Operational control is performed to obtain immediate information about the functional status of some students.

3. Functional tests on staged control should be carried out from 11 to $13 \mathrm{pm}$, when the body of the overwhelming number of students according to biorhythmology physical efficiency the most favorable react on muscle load. For this testing period, schedule of classes, if it is necessary changes so that the pair of physical education was the third or fourth timetable. Appropriate physical education classes entirely devoted to evaluation functional abilities. Bicycle exercise testing of students while current control is performed for several pairs as physical exercise included in the outline for the session. In operational control main number of students with significant positive (negative) growth dynamics and high (or low) level of functional abilities. In this stage of testing is held individually in training time and after all pairs.

4. At the beginning of the school year in the first half of September trial test are held in the form of physical exercise in the classroom for physical education. Bicycle exercise testing during staged, current and operational control in the classroom and after a pair in free time from education performed without warming up. During the functional test the teachers of physical education should monitor compliance pedaling rate of students ( $60 \mathrm{rev} / \mathrm{min}$ ). Exactly, according the planned indicators of heart rate on the reverse $\left(H R=153-156 \mathrm{~b} \cdot \mathrm{min}^{-1}\right)$ to reduce bicycle exercise loading. Follow the well-being of students while performing functional tests thus rely on external indicators of fatigue (discoloration of skin, sweating rate, respiratory rate, etc.).

5. To assess the level of functionality using approximate legislative table in terms of heart rate, physical performance, efficiency and regulation of cardiac parameters of the energy developed by the test results with the 
change of power in a closed cycle. On the bases of the assessment of functional abilities for physical education teachers correcting process of physical education in the school that would contribute the expansion of functional reserves of the body of students and improve physical health.

\section{Discussion}

In area of physical culture and sports for monitoring of physical health of pupils and students widely adopted methods for quantitative estimation of physical efficiency, among which Rufye's test, a Harvard step test and PWC170. However, the obtained results by an appropriate methods through certain inaccuracies in the obtaining results and the wrong approach of finding the appropriate indicators, which do not take into account the age-related changes that occur in organism of children and young people are low informative. Researches of such character are also accompanied, unfortunately, the lack of a common approach and accordingly the contradictory of results, as evidenced the analysis carried out by us. Some of the data not only differ significantly, but also exceed the mapped numbers almost in two times. Fluctuation ranges of physical efficiency are so great that their practical usage is possible with some caution.

According to our opinion, the method of testing the physical efficiency of the human body using a physical activity, capacity of which changes in a closed cycle (Davidenko, Andrianov, Yakovlev, 1984), corresponds to the majority of known requirements. On the basis of obtained results of physical efficiency, can be estimated the state of health as well as in complex with physical preparedness to make a correction of teaching and educational process of physical education in universities.

Given methodic is not widely used and has been used in a few studies of functional reserves of sportsmen of high qualification (Davidenko, Andrianov, Yakovlev, 1984; Bosenko, Samokish, Dubinin, 2008), and was implemented in teaching and educational process of physical education of elementary school in some educational institutions (Samokish, 2005). In open literature there are no complex researches of functional opportunities of students based on of physical efficiency and physical preparedness.

Obviously, using the proposed method of Davidenko, Andrianov, Yakovlev (1984), we can give a more accurate and comprehensive assessment to the level of functional abilities of students. According to Kornienko and Sonkyna (1999) is ergometric testing as a key component of the assessment of physical efficiency, absent in education programs. The results of the research, according to physical activity in a closed cycle with has real opportunity to get as much practice in popular usage as indicators of physical fitness, confirming the relevance and prospects of research in this area.

\section{Conclusion}

Regulations Proposed in our study give more information on the positive (negative) change in the level of functional abilities during the school year, which will help the teacher to perform the correction of the educational process, apply individual and differentiated approach in the classroom for physical education, determine the level of physical health of students etc. 


\section{References}

Bosenko, A.I., Samokish, I.I., Dubinin, A.N. (2008). Functional control of rowers by load with reverse in annual cycle of training. Journal of Physical Culture and Sport in the $21^{\text {th }}$ century, 65-70.

Coneva, T.N., Bosenko, A.I., Dudnik, A.I. (1996). Regulation mechanisms of cardiac rhythm of 9-10 years old boys in conditions of muscular load with a reverse. Journal of Adaptation Abilities of Children and Youth, 76-77.

Davidenko, D.N., Andrianov, V.P., Yakovlev, G.M. (1984). Methods of assessing the functional capacities of a load test using a closedloop power change. Ways of mobilization functional reserves of a sportsman. Journal of Collection of Research Papers, 35-41.

Domashenko, A., Raievs'ky, R., Kanishevs'ky, S. (2003). Development of national system of physical training of student youth in Ukraine. Journal of Pedagogical, Psychological and Medico-biological Problems of Physical Training and Sports, 16, 16-23.

Kornienko, I.A., Son'kin, V.D. (1999). Biological reliability, ontogenesis and age dynamics of muscular performance. Journal of Human Physiology, 1, 98-108.

Operaylo, S.I. (2006). Regulations on the organization of mass physical culture and sports in higher education. Journal of Theory and Methods of Physical Education, 5, 4-13.

Samokysh, I.I. (2005). New approaches to determination of the level of physical state of junior school girls. Journal of Pedagogy, Psychology and Medico-biological Problems of Physical Training and Sports, 3, 41-46.

Samokih, I.I., Bosenko, A.I. (2009). Assessment of too slow brain processes of 7-8 years old girls during exercise in a closed cycle. Journal of Theory and Methods of Physical Training and Sports, 2, 108-111.

Cite this article aS: Samokish, I., Bosenko, A., Pryimakov, O., Biletskaya, V. (2017). Monitoring System of Functional Ability of University Students in the Process of Physical Education. Central European Journal of Sport Sciences and Medicine, 17 (1), 73-78. DOI: 10.18276/ cej.2017.1-09. 